\title{
Aerobic Exercise Attenuates the Loss of Skeletal Muscle during Energy Restriction in Adults with Visceral Adiposity
}

\author{
Eiichi Yoshimura ${ }^{a}, b \quad$ Hideaki Kumahara ${ }^{b, c}$ Takuro Tobina ${ }^{b, d}$ \\ Takuro Matsudaa,b Kiwa Watabe ${ }^{a, b}$ Sakiko Matono ${ }^{\text {e }}$ Makoto Ayabe ${ }^{f}$

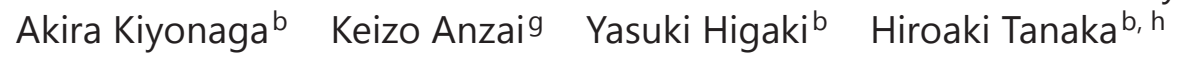 \\ ${ }^{a}$ Faculty of Medicine, ${ }^{b}$ Faculty of Sports and Health Science, Fukuoka University, ${ }^{c}$ Faculty \\ of Nutritional Sciences, Nakamura Gakuen University, Fukuoka, ${ }^{\mathrm{d}}$ Faculty of Nursing and \\ Nutrition, University of Nagasaki, Nagasaki, eFukuoka Safety Center Co., Ltd., Fukuoka, \\ ${ }^{\mathrm{f}}$ Faculty of Computer Science and Systems Engineering, Okayama Prefectural University, \\ Okayama, ${ }^{9}$ Department of Internal Medicine, Saga University, Saga, ${ }^{\text {hInstitute for Physical }}$ \\ Activity, Fukuoka University, Fukuoka, Japan
}

\section{Key Words}

Aerobic exercise $\cdot$ Skeletal muscle $\cdot$ Normal density muscle $\cdot$ Visceral adiposity $\cdot$ Energy restriction

\begin{abstract}
Objective: To evaluate the effects of energy restriction with or without aerobic exercise on thigh muscle mass and quality in adults with visceral adiposity. Methods: 75 males and females were randomly assigned to the groups 'diet only' (DO; $n=42$ ) or 'diet plus aerobic exercise' (D/Ex; $n=33$ ) for 12 weeks. The target energy intake in both groups was $25 \mathrm{kcal} / \mathrm{kg}$ of ideal body weight. Subjects in the D/Ex group were instructed to exercise for $\geq 300 \mathrm{~min} /$ week at lactate threshold. Computed tomography was used to measure thigh muscle cross-sectional area (CSA), normal-density muscle area (NDMA), and visceral fat area. Results: Total body weight (DO: $-6.6 \pm 3.6 \%$; D/Ex: $-7.3 \pm 4.6 \%$ ) and visceral fat (DO: $-16.0 \pm 13.8 \%$; D/Ex: $-23.1 \pm$ $14.7 \%)$ decreased significantly in both groups; however, the changes were not significantly different between the two groups. The decrease in muscle CSA was significantly greater in the DO group $(-5.1 \pm 4.5 \%)$ compared with the D/Ex group $(-2.5 \pm 5.0 \%)$. NDMA decreased significantly in the DO $(-4.9 \pm 4.9 \%)$ but not in the D/Ex group $(-1.4 \pm 5.0 \%)$. Conclusion: Aerobic exercise attenuated the loss of skeletal muscle during energy restriction in adults with visceral adiposity.


Yoshimura et al.: Aerobic Exercise Attenuates the Loss of Skeletal Muscle during Energy Restriction in Adults with Visceral Adiposity

\section{Introduction}

Muscle mass decreases by 1-2\% each year in middle-aged adults [1,2]. The loss of muscle strength amounts to approximately $1.5 \%$ each year between 50 and 60 years of age, and increases to $3 \%$ per year thereafter. Thus, marked declines in muscle mass and strength have already occurred by middle age, and persons in any age group must protect themselves against the loss of muscle associated with weight loss.

Abdominal obesity, particularly visceral fat accumulation, is an independent risk factor for metabolic and cardiovascular disorders $[3,4]$. Energy restriction-induced weight loss, which is the most common method of treating obesity and visceral adiposity, can be successful in achieving moderate weight loss [5]. However, energy restriction not only results in the loss of body fat mass but also causes a significant loss of fat-free mass (FFM) [5, 6]. This suggests that energy restriction-induced weight loss actually accelerates the loss of muscle mass with age, also known as sarcopenia, which induces physical frailty and increases the risk of cardiovascular diseases [7]. This may result in the decline of both activities of daily living and healthrelated quality of life. Therefore, it is essential to carefully consider the clinical approach used to treat obesity and visceral adiposity.

Chomentowski et al. [6] reported that the addition of moderate aerobic exercise to intentional diet-induced weight loss attenuated the loss of muscle mass in older, overweight to obese adults. However, Asian populations are more prone to visceral adiposity and low skeletal muscle mass compared to their Western counterparts [8]. Despite these findings, it is unclear whether exercise could help to maintain skeletal muscle mass during energy restriction in Asian (Japanese) individuals with visceral adiposity. Thus, the purpose of this study was to determine whether diet-induced weight loss plus aerobic exercise has beneficial effects on decreasing abdominal fat and metabolic parameters (circulating glucose, lipid, and inflammatory markers) and attenuates the loss of skeletal muscle mass associated with energy restriction in adults with visceral adiposity.

\section{Methods}

\section{Participants}

Males and females aged 40-75 years were recruited by advertisements in newspapers, on television, and on public transportation. Overall, 146 subjects were contacted to be participants, and 89 subjects were eligible to be enrolled in the Metabolic Syndrome Prevention/Improvement Intervention Program. Before baseline measurements, subjects were randomized to receive one of two interventions, each lasting 12 weeks: diet-induced weight loss (DO; $\mathrm{n}=45$ ) or diet-induced weight loss combined with aerobic exercise (D/ Ex; $n=44$ ). The participants enrolled in this study i) had visceral adiposity (visceral fat area $\geq 100 \mathrm{~cm}^{2}$ ), ii) were not taking any medications affecting glucose metabolism to avoid potential confounding effects on weight change, and iii) had no thyroid disease. Of the 14 subjects who did not complete the program (D0: $n$ = 3; D/Ex: $\mathrm{n}=11$ ), 5 left for employment-related reasons, 4 had a metabolic disorder or ileus, 2 were lost to follow-up, 2 had poor physical condition during the 12-week intervention, and 1 left for family reasons. Thus, 75 males and females completed the 12-week intervention, with 42 in the DO group (18 males and 24 females) and 33 in the D/Ex group (13 males, 20 females). As a result, the present study only analyzed data from participants who completed the measures at both baseline and the end of the study. The characteristics of the subjects who completed the intervention were not significantly different between the groups regarding age, male:female ratio, anthropometric variables, or metabolic parameters at baseline. All subjects gave informed consent after agreeing with the purpose, methods, and significance of the study. This study was approved by the Ethics Committee of Fukuoka University.

Exercise Protocol

Participants were instructed to perform 20 min each of step exercises, bicycle ergometry, and walking or running (60 min per session) three times per week under the supervision of exercise trainers. They were 
Yoshimura et al.: Aerobic Exercise Attenuates the Loss of Skeletal Muscle during Energy Restriction in Adults with Visceral Adiposity

Table 1. Effects of diet-induced weight loss with or without aerobic exercise on anthropometric parameters, aerobic capacity, dietary intake, and physical activity

\begin{tabular}{|c|c|c|c|c|c|}
\hline & \multicolumn{2}{|l|}{ DO group } & \multicolumn{2}{|l|}{ D/Ex group } & \multirow{2}{*}{$\begin{array}{l}\text { Group } \times \text { time, } \\
\text { p value }\end{array}$} \\
\hline & pre & post & pre & post & \\
\hline Weight, kg & $72.2 \pm 11.9$ & $67.2 \pm 10.1^{* * *}$ & $71.2 \pm 13.7$ & $65.9 \pm 12.9^{* * *}$ & 0.652 \\
\hline BMI, $\mathrm{kg} / \mathrm{m}^{2}$ & $28.0 \pm 3.4$ & $26.2 \pm 3.0^{* * *}$ & $27.8 \pm 3.8$ & $25.7 \pm 3.5^{* * *}$ & 0.445 \\
\hline Percentage of body fat, $\%^{\mathrm{a}}$ & $34.2 \pm 7.3$ & $31.3 \pm 7.7^{* * *}$ & $34.1 \pm 6.4$ & $30.4 \pm 6.9^{* * *}$ & 0.361 \\
\hline Fat mass, $\mathrm{kg}^{\mathrm{a}}$ & $25.0 \pm 6.9$ & $21.3 \pm 6.1^{* * *}$ & $23.8 \pm 5.7$ & $19.6 \pm 5.4^{* * *}$ & 0.546 \\
\hline FFM, $\mathrm{kg}^{\mathrm{a}}$ & $48.0 \pm 9.2$ & $46.7 \pm 8.6^{* *}$ & $46.4 \pm 10.2$ & $45.1 \pm 9.5^{* * *}$ & 0.936 \\
\hline Visceral fat area, $\mathrm{cm}^{2}$ & $182 \pm 54$ & $151 \pm 44^{* * *}$ & $183 \pm 52$ & $140 \pm 46^{* * *}$ & 0.104 \\
\hline Subcutaneous fat area, $\mathrm{cm}^{2}$ & $284 \pm 108$ & $252 \pm 102^{* * *}$ & $281 \pm 92$ & $241 \pm 90^{* * *}$ & 0.333 \\
\hline $\mathrm{VO}_{2 \text { peak }}, \mathrm{ml} / \mathrm{min} / \mathrm{kg} \mathrm{FFM}^{\mathrm{b}}$ & $33.0 \pm 6.2$ & $31.2 \pm 5.3^{*}$ & $32.2 \pm 5.7$ & $36.0 \pm 7.8^{*}$ & 0.001 \\
\hline Step counts, steps/dayc & $6,645 \pm 2,492$ & $7,116 \pm 2,902$ & $6,602 \pm 3,004$ & $9,195 \pm 3,711^{* * *}$ & 0.001 \\
\hline Energy intake, kcal/day ${ }^{\mathrm{d}}$ & $2,008 \pm 385$ & $1,526 \pm 300^{* * *}$ & $2,000 \pm 316$ & $1,618 \pm 330^{* * *}$ & 0.180 \\
\hline Protein, g/day & $75 \pm 18$ & $63 \pm 13^{* * *}$ & $82 \pm 16$ & $68 \pm 17^{* * *}$ & 0.822 \\
\hline Fat, g/day ${ }^{\mathrm{d}}$ & $60 \pm 15$ & $43 \pm 12^{* * *}$ & $60 \pm 15$ & $47 \pm 14^{* * *}$ & 0.314 \\
\hline Carbohydrate, g/day ${ }^{\mathrm{d}}$ & $269 \pm 53$ & $211 \pm 42^{* * *}$ & $267 \pm 51$ & $224 \pm 44^{* * *}$ & 0.179 \\
\hline
\end{tabular}

DO group = Diet-induced weight loss group; D/Ex group = diet-induced weight loss with aerobic exercise group; FFM = fat-free mass.

${ }^{a} D O(n=38), D / E x(n=32) .{ }^{b} D O(n=38), D / E x(n=31) . ~{ }^{c} D O(n=34), D / E x(n=29) .{ }^{d} D O(n=38), D / E x(n=30)$.

Pre vs. post: ${ }^{*} \mathrm{p}<0.05,{ }^{* *} \mathrm{p}<0.01,{ }^{* * *} \mathrm{p}<0.001$.

also instructed to carry out a further $120 \mathrm{~min}$ of exercise per week on their own at home in order to ensure a total of $\geq 300$ min of moderate exercise per week. The exercise intensity was set at lactate threshold (LT). The LT intensity of bicycle ergometer training (W) was determined from an incremental exercise test on a bicycle ergometer, as described below. The LT intensity of step exercise was determined by using a submaximal graded step test [9]. The intensity of walking or jogging was controlled by heart rate (HR) at the LT intensity, which was determined by the step exercise test. HR was measured using a HR monitor (Polar FT1; Polar Electro, Kempele, Finland). The exercise sessions completed the participant's homes (stepping and walking or jogging) were performed using provided bench steps and HR monitors. Each participant recorded all exercise sessions, including the duration ( $\mathrm{min}$ ), mode, and HR, which were reviewed every other week to assess exercise adherence. All subjects underwent workload modifications at least 6 weeks after starting the program. According to the participant's diary (exercise duration and body weight (BW)) and exercise intensity (metabolic equivalent (MET)) at the prescribed LT, the estimated energy expenditure per day (kcal/day) during exercise was calculated using the following formula [10]: 'BW (kg) $\times($ MET value -1 MET) $\times$ exercise duration (h/day).' The maximum HRs were calculated using the formula proposed by the American College of Sports Medicine (ACSM) [11]: HRmax = $206.9-(0.67 \times$ age $)$.

\section{Energy Restriction}

Daily energy needs were determined by multiplying the participant's ideal BW equivalent of a BMI of 22 $\mathrm{kg} / \mathrm{m}^{2}$ by 25 . The participants received weekly guidance from skilled dieticians (face-to-face) who recommended appropriate daily nutrition using lectures and counseling. The sessions included adjustments of caloric intake and behavioral therapy. Food diaries were reviewed every week, and participants were given instruction on food intake based on the prescribed energy intake. The participants were instructed to measure their weight daily.

\section{Dietary Records}

To calculate energy intake (in kcal) and the intake of fat, protein, and carbohydrate (in grams), each participant completed a self-recorded food intake diary before and at 10-12 weeks following the intervention. Subjects were asked to record food intake over 3 days, including 2 weekdays and either a Saturday or a Sunday. All meals were to be photographed to increase the accuracy of the measurement. Skilled dieticians analyzed the data (table 1 ). 
Yoshimura et al.: Aerobic Exercise Attenuates the Loss of Skeletal Muscle during Energy Restriction in Adults with Visceral Adiposity

Physical Activity

Physical activity (step count) was measured using a small uniaxial accelerometer (Lifecorder Ex; Suzuken Co., Ltd., Nagoya, Japan) [12]. Subjects wore the accelerometer, except while sleeping or bathing, for 2 weeks before the intervention and during the 10-12 weeks of the intervention. The accelerometer was sealed so that the subjects could not gain access to the physical activity measurements. All measured variables were averaged over the last 7 days of the measurement period to assess physical activity in free-living conditions.

Anthropometric Measurements and Body Composition

All anthropometric measurements and body composition were conducted after a fast lasting more than $12 \mathrm{~h}$. BW was measured to the nearest $0.01 \mathrm{~kg}$ using electronic scales (Shinko Denshi Vibra Co., Ltd., Tokyo, Japan). Height was measured to the nearest $0.1 \mathrm{~cm}$ using a stadiometer. BMI was calculated as $\mathrm{kg} / \mathrm{m}^{2}$. Body composition was measured using the underwater weighing method, and body density was estimated after correction for residual air by the $\mathrm{O}_{2}$ re-breathing method during underwater weighing [13]. Body fat percentage was calculated using the formula of Brozek et al. [13]. Fat mass (FM) and FFM were calculated using the formula 'BW $\times$ body fat percentage / 100' and 'BW - FM'.

\section{Computed Tomography}

Computed tomography (CT) scans were performed as previously described [14]. Visceral fat area (VFA) and subcutaneous fat area (SFA) were assessed at the L4-L5 intervertebral disc space. CT was also used to measure the cross-sectional area (CSA) of the mid-thigh muscle in both legs. Low-density muscle area (LDMA), a marker of lipid-rich skeletal muscle and normal-density muscle area (NDMA), which contains a lower lipid content, were also quantified $[6,15]$. All subjects fasted for at least $3 \mathrm{~h}$ before CT scans but were allowed to drink water.

\section{Blood Biochemistry}

Blood samples were obtained from the antecubital vein in the morning after a 12-hour overnight fast. Serum biochemistry analysis was conducted by SRL Inc. (Tokyo, Japan). The biochemical parameters included: interleukin-6 (IL-6), insulin (chemiluminescent enzyme immunoassays), high-sensitive C-reactive protein (hsCRP; nephelometry method), high-molecular-weight adiponectin, TNF- $\alpha$ (enzyme-linked immunosorbent assays), glucose (ultraviolet/hexokinase method), triglyceride (enzyme method), high-density lipoprotein (HDL; direct method), leptin (radioimmunoassays), and hemoglobin A1c (HbA1c; latex agglutination method). HbA1c (\%) is presented as the National Glycohemoglobin Standardization Program (NGSP) value, which was calculated using the conversion equation for HbA1c derived by the Japan Diabetes Society (JDS): HbA1c (NGSP; \%) = $1.02 \times$ HbA1c (JDS; \%) + 0.25\% [16]. Homeostasis model assessment of insulin resistance (HOMA-IR) was calculated as a marker for systemic insulin resistance using the formula reported by Matthews et al. [17]: HOMA-IR = glucose $\times$ insulin/405.

\section{Aerobic Work Capacity}

Aerobic work capacity was performed as previously described [14]. The test of aerobic work capacity was continued until subjective exhaustion using a bicycle ergometer (Rehcor; Lode BV, Groningen, The Netherlands) to determine the peak oxygen uptake $\left(\mathrm{VO}_{2}\right.$ peak $) . \mathrm{VO}_{2 \text { peak }}$ was adjusted for FFM.

\section{Statistical Analysis}

All data are presented as means \pm standard deviation (SD), and the level of significance for all statistical tests was set at $\mathrm{p}<0.05$. hSCRP was logarithmically transformed to approximate a normal distribution. Baseline characteristics were compared between the two groups using unpaired one-way analysis of variance (ANOVA). Repeated-measures ANOVA was used to compare dependent variables as a function of group (DO and D/Ex) and time (pre- and post-intervention). Within-group differences (baseline vs. post-intervention) were assessed by paired t-tests. SPSS version 12.0 (SPSS Inc., Chicago, IL, USA) was used for all statistical analyses. 
Yoshimura et al.: Aerobic Exercise Attenuates the Loss of Skeletal Muscle during

Table 2. Effects of diet-induced weight loss with or without aerobic exercise on blood pressure and metabolic parameters

\begin{tabular}{|c|c|c|c|c|c|}
\hline & \multicolumn{2}{|l|}{ DO group } & \multicolumn{2}{|c|}{ D/Ex group } & \multirow{2}{*}{$\begin{array}{l}\text { Group } \times \text { time, } \\
p \text { value }\end{array}$} \\
\hline & pre & post & pre & post & \\
\hline $\mathrm{SBP}, \mathrm{mm} \mathrm{Hg}{ }^{\mathrm{a}}$ & $139 \pm 18$ & $131 \pm 20^{* * *}$ & $137 \pm 20$ & $129 \pm 18^{* *}$ & 0.914 \\
\hline $\mathrm{DBP}, \mathrm{mm} \mathrm{Hg}{ }^{\mathrm{a}}$ & $87 \pm 12$ & $82 \pm 11^{* *}$ & $84 \pm 11$ & $79 \pm 10^{* *}$ & 0.946 \\
\hline Glucose, mg/dl & $103 \pm 13$ & $99 \pm 10^{* *}$ & $104 \pm 13$ & $99 \pm 8^{* *}$ & 0.870 \\
\hline Insulin, $\mu \mathrm{IU} / \mathrm{ml}$ & $8.6 \pm 3.9$ & $6.6 \pm 2.7^{* * *}$ & $10.0 \pm 6.1$ & $6.7 \pm 3.9^{* * *}$ & 0.165 \\
\hline $\mathrm{HDL}, \mathrm{mg} / \mathrm{dl}$ & $52 \pm 13$ & $52 \pm 14$ & $52 \pm 13$ & $54 \pm 12^{*}$ & 0.096 \\
\hline Triglyceride, $\mathrm{mg} / \mathrm{dl}^{\mathrm{b}}$ & $149 \pm 83$ & $119 \pm 68^{* *}$ & $132 \pm 61$ & $86 \pm 33^{* * *}$ & 0.249 \\
\hline Interleukin-6, $\mathrm{pg} / \mathrm{ml}^{\mathrm{c}}$ & $2.3 \pm 2.4$ & $1.5 \pm 1.3^{*}$ & $4.8 \pm 13.4$ & $1.8 \pm 3.1$ & 0.296 \\
\hline $\mathrm{TNF}-\alpha, \mathrm{pg} / \mathrm{ml}^{\mathrm{d}}$ & $1.2 \pm 0.6$ & $1.1 \pm 0.6$ & $1.2 \pm 0.5$ & $1.1 \pm 0.4^{* *}$ & 0.115 \\
\hline Leptin, ng/ml & $12.4 \pm 7.4$ & $8.6 \pm 6.7^{* * *}$ & $11.3 \pm 6.2$ & $6.5 \pm 3.9^{* * *}$ & 0.211 \\
\hline hsCRPe,f & $2.9 \pm 0.5$ & $2.5 \pm 0.3^{* * *}$ & $3.0 \pm 0.5$ & $2.7 \pm 0.5^{* *}$ & 0.230 \\
\hline $\begin{array}{l}\text { High molecular weight } \\
\text { adiponectin, } \mu \mathrm{g} / \mathrm{ml}\end{array}$ & $5.0 \pm 3.2$ & $5.4 \pm 3.1^{*}$ & $4.9 \pm 3.1$ & $5.5 \pm 3.1^{* *}$ & 0.392 \\
\hline HOMA-IR & $2.3 \pm 1.3$ & $1.6 \pm 0.7^{* * *}$ & $2.7 \pm 1.9$ & $1.7 \pm 1.1^{* * *}$ & 0.208 \\
\hline $\mathrm{HbA1c}, \%^{\mathrm{e}}$ & $5.6 \pm 0.4$ & $5.5 \pm 0.4^{* *}$ & $5.7 \pm 0.5$ & $5.5 \pm 0.4^{* * *}$ & 0.315 \\
\hline
\end{tabular}

DO group = Diet-induced weight loss group; D/Ex group = diet-induced weight loss with aerobic exercise group.

${ }^{a}$ DO ( $\left.=40\right), D / \operatorname{Ex}(n=33) \cdot{ }^{b} D O(n=42), D / E x(n=32) .{ }^{c} D O(n=41), D / E x(n=31) .{ }^{d} D O(n=39), D / E x$ $(\mathrm{n}=31) .{ }^{\mathrm{e}} \mathrm{DO}(\mathrm{n}=41), \mathrm{D} / \mathrm{Ex}(\mathrm{n}=33) .{ }^{\mathrm{f}} \mathrm{hsCRP}$ was logarithmically transformed to approximate a normal distribution.

Pre vs. post: ${ }^{*} \mathrm{p}<0.05,{ }^{* *} \mathrm{p}<0.01,{ }^{* * *} \mathrm{p}<0.001$.

\section{Results}

\section{Baseline Data and Intervention Adherence}

There were no significant differences in age, anthropometric parameters, thigh muscle area, or metabolic parameters between the DO and D/Ex groups at baseline. The mean proportion of weekly supervised exercise sessions attended during the 12-week intervention was $81 \pm 16 \%$. The mean durations of exercise performed at home and of total exercise were $127 \pm 80 \mathrm{~min} /$ week and $273 \pm 87 \mathrm{~min} /$ week, respectively. The percentages of $\mathrm{VO}_{2 \text { peak }}$ at $\mathrm{LT}$ $\left(\% \mathrm{VO}_{2}\right.$ peak $)$, predicted maximal $\mathrm{HR}\left(\% \mathrm{HR}_{\max }\right)$, and METs during exercise (prescribed LT intensity) were $55.1 \pm 11.9 \% \mathrm{VO}_{2 \text { peak }}, 64.3 \pm 9.6 \% \mathrm{HR}_{\max }$, and $5.3 \pm 0.8 \mathrm{METs}$. The estimated energy expenditure attributable to exercise was $263 \pm 117 \mathrm{kcal} /$ day. The rates of attendance at nutritional guidance sessions averaged over the 12 -week intervention were $97 \pm 7 \%$ in the D0 group and $93 \pm 9 \%$ in the D/Ex group. In both groups, less than one-third of the subjects achieved the target daily energy intake (DO 33\% vs. D/Ex 27\%).

Effects of Diet-Induced Weight Loss with or without Aerobic Exercise on Anthropometric

Parameters, Aerobic Capacity, Dietary Intake, and Physical Activity

There were no significant interaction effects between group and time for the anthropometric parameters (BW, BMI, body fat percentage, FM, FFM, VFA, and SFA) and for dietary intake (table 1). In addition, decreases in BW, BMI, body fat percentage, FM, FFM, VFA, SFA, and dietary intake were similar in both groups. $\mathrm{VO}_{2}$ peak increased to a greater extent in the D/Ex group compared with the DO group; the increase from baseline to post-intervention was significant in the D/Ex group, but not in the DO group. The mean step count also increased 


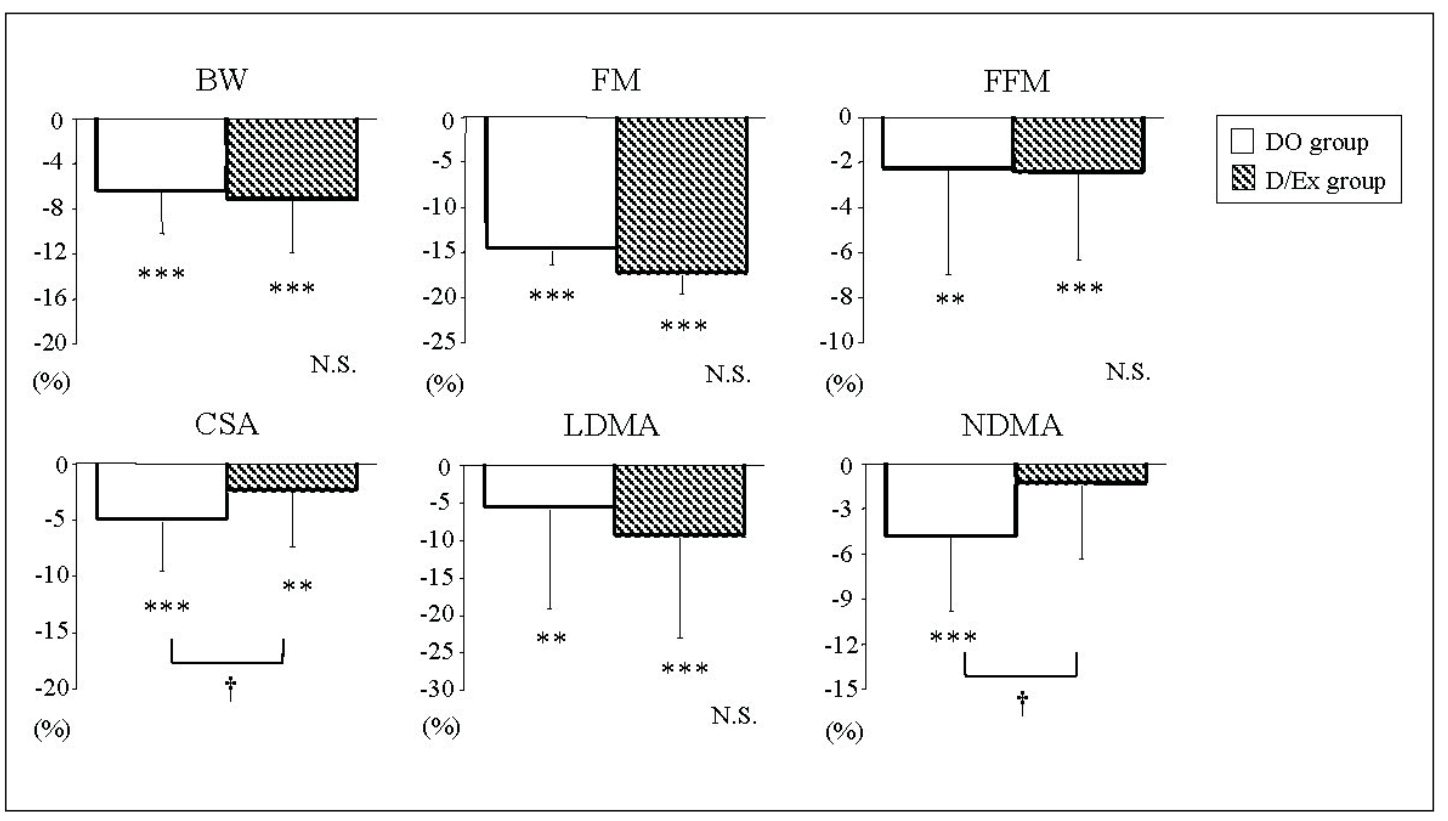

Fig. 1. Percent changes in BW, FM, and FFM (as measured by the underwater method), and thigh muscle area (as measured by CT). Decreases in BW, FM, FFM, and LDMA were similar in both groups. Decreases in CSA and NDMA were greater in the DO group compared with the D/Ex group. ${ }^{* *} \mathrm{p}<0.01$ and ${ }^{* * *} \mathrm{p}<0.001$ versus baseline. ${ }^{\dagger}$ The interaction effect was statistically significant. N.S. = Not significant; DO = diet-induced weight loss only; D/Ex = diet-induced weight loss with aerobic exercise; BW = body weight; FM = fat mass; FFM = fat-free mass; CSA = cross-sectional area; LDMA = low-density muscle area; NDMA = normal-density muscle area.

to a greater extent in the D/Ex group compared with the DO group; the increase from baseline to post-intervention was significant in the D/Ex group, but not in the DO group.

\section{Effects of Diet-Induced Weight Loss with or without Aerobic Exercise on Blood Pressure} and Metabolic Parameters

There was no significant interaction effect between group and time on blood pressure or metabolic parameters. Systolic and diastolic blood pressure decreased in both groups from baseline to post-intervention. In addition, there were significant decreases in glucose, insulin, triglyceride, leptin, hsCRP, HOMA-IR, and HbA1c in both groups. HDL increased significantly and TNF- $\alpha$ decreased significantly in the D/Ex group, but not in the DO group (table 2).

\section{Percent Changes in BW, FM, FFM, and Thigh Muscle Area}

There was no significant interaction effect between group and time for the percent changes in BW, FM, or FFM. CSA decreased in both groups, although the decrease was greater in the DO group compared with the D/Ex group (fig. 1). LDMA, which represents high lipid content, decreased significantly in both groups, without significant differences between the two groups. The decrease in NDMA, which represents lower lipid content, was greater in the DO group compared with the D/Ex group, although the loss of muscle area was only significant in the DO group. 
Yoshimura et al.: Aerobic Exercise Attenuates the Loss of Skeletal Muscle during Energy Restriction in Adults with Visceral Adiposity

\section{Discussion}

The main finding of this study was that diet-induced weight loss in addition to aerobic exercise attenuated the loss of thigh skeletal muscle mass associated with energy restriction alone in middle-aged to elderly adults with visceral adiposity. Conversely, diet-induced weight loss alone was associated with reductions in both FFM and thigh skeletal muscle mass. Chomentowski et al. [6] reported that moderate aerobic exercise attenuated the loss of lean muscle mass caused by energy restriction. Diet-induced weight loss that can successfully achieve a weight loss of $5-10 \%$ within a short period of time can greatly improve blood pressure as well as glucose and lipid metabolism [18-20]. These results suggest that intentional weight loss with diet/energy restriction can improve various metabolic parameters associated with obesity and visceral adiposity but may also increase the risk of sarcopenia, which occurs with aging in association with the loss of muscle [21,22]. Thus, the addition of aerobic exercise to diet-induced weight loss may offer an effective strategy to prevent sarcopenia and may achieve better weight loss compared with diet alone.

The present study indicated that FFM (using the underwater method) decreased in both groups. Previous studies have revealed that the decrease in body mass does not differ between diet- and diet plus exercise-induced weight loss regimens, although diet-induced weight loss reduced FFM (as assessed by dual-energy X-ray absorptiometry (DXA)) more than dietinduced weight loss plus exercise $[6,22]$. However, an earlier study indicated that $6.8 \%$ of FFM was lost during an exercise intervention [23]. This study also suggested that changes in FFM are comparable to changes in appendicular lean soft tissue during energy restriction with or without exercise. The reason for this apparent discrepancy is unclear, but it is possible that differences in methods (DXA vs. underwater method) [24, 25] or the composition of the FFM lost (i.e. water, protein, and mineral masses) [26] may be potential explanations.

Interestingly, this study revealed that the improvements in metabolic parameters (including insulin resistance) and the reduction of abdominal fat did not differ between the two groups. Previous studies have also reported that exercise can reduce visceral fat content without inducing weight loss [27, 28]. However, Christiansen et al. [29] reported that a relatively large weight loss of $\geq 5-7 \%$ has beneficial effects on the circulating levels of inflammatory markers in obese subjects, whereas aerobic exercise had no effects on these markers. Furthermore, Weiss et al. [30] suggested that the addition of exercise to energy restriction does not appear to have additive effects on changes in metabolic parameters or show improvements in glucose tolerance if exercise training is discontinued for $\geq 2$ days. In the present study, the D/Ex group was assessed 2 days after the last exercise training session to determine the chronic effects of aerobic exercise on metabolic parameters, including insulin resistance. Therefore, the results of the studies described above may be consistent with the current results.

In the present study, there were no significant interaction effects between group and time on dietary intake $(\mathrm{p}=0.180)$. The estimated energy expenditure attributable to exercise in the D/Ex group was $263 \pm 117 \mathrm{kcal} /$ day, which would account for a loss of FM of $3.0 \pm 1.3$ kg over 12 weeks (where $1.0 \mathrm{~g}$ of fat equals $7.2 \mathrm{kcal}$ ). Nevertheless, the D/Ex group did not lose more weight than the DO group. While there are conflicting reports [31], our results are consistent with those of earlier studies, which indicate that the magnitude of these changes is not substantially different between diet alone and diet plus exercise [6, 22, 29]. A metaanalysis also suggested that weight loss achieved with diet alone or diet plus exercise is not significantly different $(10.7 \pm 0.5$ vs. $11.0 \pm 0.6 \mathrm{~kg})$ [32]. The D/Ex group was instructed to perform $\geq 300 \mathrm{~min}$ of exercise each week; however, this ranged from 199 to $325 \mathrm{~min}$. Therefore, not all participants in this group conducted $\geq 250$ min of exercise per week, which is a threshold level for clinically significant weight loss set by the ACSM [33]. Furthermore, 
Yoshimura et al.: Aerobic Exercise Attenuates the Loss of Skeletal Muscle during Energy Restriction in Adults with Visceral Adiposity

Thomas et al. [34] have reported that the small magnitude of weight loss observed from the majority of evaluated exercise interventions is primarily due to low doses of prescribed exercise energy expenditures compounded by a concomitant increase in caloric intake. This result suggests that the additional effects of diet and exercise are difficult to anticipate, as suggested by the results of previous studies [6, 22, 29].

Aerobic capacity was clearly increased in the D/Ex group, but not in the DO group. The increase in $\mathrm{VO}_{2 \text { peak }}$ in the $\mathrm{D} /$ Ex group is an important and clinically relevant outcome. It is well documented that greater aerobic capacity is associated with greater longevity and reduced risks of type 2 diabetes, coronary heart disease, stroke, and colon cancer [35, 36]. Aerobic exercise may also benefit aging skeletal muscle by enhancing mitochondrial bioenergetics [37], conferring improvements in insulin sensitivity and/or decreased oxidative stress. Thus, while attenuation of sarcopenia in the thigh muscle is important, the additional benefits of aerobic exercise on increasing aerobic capacity have several clinical implications, including the potential for future increases in activities of daily living and health-related quality of life in middle-aged and older adults. Therefore, our finding that diet-induced weight loss plus aerobic exercise improves aerobic capacity is important in terms of longevity and metabolic disorders.

There are two limitations associated with the present study. Firstly, the sample size was small, included males and females, and the age range was relatively wide. However, the influence of sex as a limitation may be negligible based on the study by Christiansen et al. [29] who found no sex-specific differences of exercise or diet-induced weight loss on metabolic or inflammatory factors, indicating that males and females would respond similarly to a 12 -week randomized intervention study. We also found that the decrease in thigh skeletal muscle mass was smaller in the D/Ex group compared with the DO group, even after adjusting for age in ANOVA (DO vs. D/Ex, $p=0.021$ ). Therefore, the age range of subjects is unlikely to affect the results of this study. Secondly, exclusion criteria for the present study included antidiabetic therapy to avoid possible confounding effects on weight change, although subjects receiving antihypertensive and antihyperlipidemic drugs were eligible. However, even if we excluded these participants who were taking such drugs from the analysis, the results were unchanged. Future studies should establish a study protocol for further evaluation (e.g. aerobic training vs. resistance training, and normal diet-induced weight loss vs. high protein diet-induced weight loss with or without exercise).

In conclusion, the present findings suggest that diet-induced weight loss plus aerobic exercise decreases abdominal fat (i.e. visceral and subcutaneous fat) and circulating metabolic parameters, and also attenuates the loss of thigh skeletal muscle mass associated with diet-induced weight loss in middle-aged to elderly adults with visceral adiposity.

\section{Acknowledgments}

This study was supported by the Central Research Institute for Physical Activity (A19200049 Strategic Research Infrastructure) from the Japanese Government's Ministry of Education, Culture, Sports, Science and Technology, and a Global FU Program grant from Fukuoka University.

The authors are indebted to the participants of this study for their enthusiasm and cooperation, and to the staff and graduate students of the Laboratory of Exercise Physiology, Fukuoka University, who assisted with data collection, exercise supervision, and dietary counseling. Finally, we wish to thank Dr. Kyogo Kurita, Dr. Hiroaki Sato, and Dr. Koji Midorikawa of Fukuseikai Hospital, Fukuoka, Japan, for their technical assistance with CT examinations.

\section{Disclosure Statement}

The authors have no conflicts of interest to declare. 
Yoshimura et al.: Aerobic Exercise Attenuates the Loss of Skeletal Muscle during

Energy Restriction in Adults with Visceral Adiposity

\section{References}

1 Sehl ME, Yates FE: Kinetics of human aging: I. Rates of senescence between ages 30 and 70 years in healthy people. J Gerontol A Biol Sci Med Sci 2001;56:198-208.

2 Doherty TJ: Invited review: Aging and sarcopenia. J Appl Physiol 2003;95:1717-1727.

3 Goldstein DJ: Beneficial health effects of modest weight loss. Int J Obes Relat Metab Disord 1992;16:397-415.

4 Nakamura T, Tokunaga K, Shimomura I, Nishida M, Yoshida S, Kotani K, Islam AH, Keno Y, Kobatake T, Nagai Y: Contribution of visceral fat accumulation to the development of coronary artery disease in non-obese men. Atherosclerosis 1994;107:239-246.

5 Weinheimer EM, Sands LP, Campbell WW: A systematic review of the separate and combined effects of energy restriction and exercise on fat-free mass in middle-aged and older adults: implications for sarcopenic obesity. Nutr Rev 2010;68:375-388.

6 Chomentowski P, Dubé JJ, Amati F, Stefanovic-Racic M, Zhu S, Toledo FG, Goodpaster BH: Moderate exercise attenuates the loss of skeletal muscle mass that occurs with intentional caloric restriction-induced weight loss in older, overweight to obese adults. J Gerontol A Biol Sci Med Sci 2009;64:575-580.

7 Sanada K, Iemitsu M, Murakami H, Gando Y, Kawano H, Kawakami R, Tabata I, Miyachi M: Adverse effects of coexistence of sarcopenia and metabolic syndrome in Japanese women. Eur J Clin Nutr 2012;66:1093-1098.

8 Chan JC, Malik V, Jia W, Kadowaki T, Yajnik CS, Yoon KH, Hu FB: Diabetes in Asia: epidemiology, risk factors, and pathophysiology. JAMA 2009;301:2129-2140.

-9 Ayabe M, Yahiro T, Mori Y, Takayama K, Tobina T, Higuchi H, Ishii K, Sakuma I, Yoshitake Y, Miyazaki H, Kiyonaga A, Shindo M, Tanaka H: Simple assessment of lactate threshold by means of the bench stepping in older population. Int J Sport Health Sci 2003;1:207-215.

10 Ainsworth BE, Haskell WL, Leon AS, Jacobs DR Jr, Montoye HJ, Sallis JF, Paffenbarger RS Jr: Compendium of physical activities: classification of energy costs of human physical activities. Med Sci Sports Exerc 1993;25: 71-80.

11 American College of Sports Medicine: ACSM's Guidelines for Exercise Testing and Prescription, ed 8. Philadelphia, Lippincott Williams \& Wilkins; 2009.

12 Kumahara H, Schutz Y, Ayabe M, Yoshioka M, Yoshitake Y, Shindo M, Ishii K, Tanaka H: The use of uniaxial accelerometry for the assessment of physical-activity-related energy expenditure: a validation study against whole-body indirect calorimetry. Br J Nutr 2004;91:235-243.

13 Goldman R: A method for underwater weighing and the determination of body density; in Brozek J, Hershel A (eds): Techniques for Measuring Body Composition. Washington, DC, National Research Council, 1961, pp 78-89.

14 Yoshimura E, Kumahara H, Tobina T, Ayabe M, Matono S, Anzai K, Higaki Y, Kiyonaga A, Tanaka H: A 12-week aerobic exercise program without energy restriction improves intrahepatic fat, liver function and atherosclerosis-related factors. Obes Res Clin Pract 2011;5:e249-e257.

15 Goodpaster BH, Kelley DE, Thaete FL, He J, Ross R: Skeletal muscle attenuation determined by computed tomography is associated with skeletal muscle lipid content. J Appl Physiol 2000;89:104-110.

16 Kashiwagi A, Kasuga M, Araki E, et al: International clinical harmonization of glycated hemoglobin in Japan: from Japan Diabetes Society to National Glycohemoglobin Standardization Program values. J Diabetes Invest 2012;3:32-40.

$\checkmark 17$ Matthews DR, Hosker JP, Rudenski AS, Naylor BA, Treacher DF, Turner RC: Homeostasis model assessment: insulin resistance and beta-cell function from fasting plasma glucose and insulin concentrations in man. Diabetologia 1985;28:412-419.

18 Williamson D, Serdula M, Anda R, Levy A, Byers T: Weight loss attempts in adults: goals, duration, and rate of weight loss. Am J Public Health 1992;82:1251-1257.

19 Clinical Guidelines on the Identification, Evaluation, and Treatment of Overweight and Obesity in Adults - The Evidence Report. National Institutes of Health. Obes Res 1998;6:51S-209S.

-20 Knowler WC, Barrett-Connor E, Fowler SE, Hamman RF, Lachin JM, Walker EA, Nathan DM; Diabetes Prevention Program Research Group: Reduction in the incidence of type 2 diabetes with lifestyle intervention or metformin. N Engl J Med 2002;346:393-403.

-21 Newman AB, Lee JS, Visser M, Goodpaster BH, Kritchevsky SB, Tylavsky FA, Nevitt M, Harris TB: Weight change and the conservation of lean mass in old age: the Health, Aging and Body Composition Study. Am J Clin Nutr 2005;82:872-878.

-22 Frimel TN, Sinacore DR, Villareal DT: Exercise attenuates the weight-loss-induced reduction in muscle mass in frail obese older adults. Med Sci Sports Exerc 2008;40:1213-1219.

23 Bopp MJ, Houston DK, Lenchik L, Easter L, Kritchevsky SB, Nicklas BJ: Lean mass loss is associated with low protein intake during dietary-induced weight loss in postmenopausal women. J Am Diet Assoc 2008;108: 1216-1220.

24 Das SK, Roberts SB, Kehayias JJ, Wang J, Hsu LK, Shikora SA, Saltzman E, McCrory MA: Body composition assessment in extreme obesity and after massive weight loss induced by gastric bypass surgery. Am J Physiol Endocrinol Metab 2003;284:1080-1088.

25 Snead DB, Birge SJ, Kohrt WM: Age-related differences in body composition by hydrodensitometry and dualenergy X-ray absorptiometry. J Appl Physiol 1993;74:770-775. 
Yoshimura et al.: Aerobic Exercise Attenuates the Loss of Skeletal Muscle during Energy Restriction in Adults with Visceral Adiposity

$>26$ Fogelholm GM, Sievänen HT, van Marken Lichtenbelt WD, Westerterp KR: Assessment of fat-mass loss during weight reduction in obese women. Metabolism 1997;46:968-975.

-27 Ross R, Dagnone D, Jones PJ, Smith H, Paddags A, Hudson R, Janssen I: Reduction in obesity and related comorbid conditions after diet-induced weight loss or exercise-induced weight loss in men. A randomized, controlled trial. Ann Intern Med 2000;133:92-103.

28 Johnson NA, Sachinwalla T, Walton DW, Smith K, Armstrong A, Thompson MW, George J: Aerobic exercise training reduces hepatic and visceral lipids in obese individuals without weight loss. Hepatology 2009;50: 1105-1112.

29 Christiansen T, Paulsen SK, Bruun JM, Pedersen SB, Richelsen B: Exercise training versus diet-induced weightloss on metabolic risk factors and inflammatory markers in obese subjects: a 12-week randomized intervention study. Am J Physiol Endocrinol Metab 2010;298:824-831.

30 Weiss EP, Racette SB, Villareal DT, Fontana L, Steger-May K, Schechtman KB, Klein S, Holloszy JO; Washington University School of Medicine CALERIE Group: Improvements in glucose tolerance and insulin action induced by increasing energy expenditure or decreasing energy intake: a randomized controlled trial. Am J Clin Nutr 2006;84:1033-1042.

-31 Okura T, Nakata Y, Lee DJ, Ohkawara K, Tanaka K: Effects of aerobic exercise and obesity phenotype on abdominal fat reduction in response to weight loss. Int J Obes (Lond) 2005;29:1259-1266.

-32 Miller WC, Koceja DM, Hamilton EJ: A meta-analysis of the past 25 years of weight loss research using diet, exercise or diet plus exercise intervention. Int J Obes Relat Metab Disord 1997;21:941-947.

33 Donnelly JE, Blair SN, Jakicic JM, Manore MM, Rankin JW, Smith BK; American College of Sports Medicine: American College of Sports Medicine Position Stand. Appropriate physical activity intervention strategies for weight loss and prevention of weight regain for adults. Med Sci Sports Exerc 2009;41:459-471.

34 Thomas DM, Bouchard C, Church T, Slentz C, Kraus WE, Redman LM, Martin CK, Silva AM, Vossen M, Westerterp K, Heymsfield SB: Why do individuals not lose more weight from an exercise intervention at a defined dose? An energy balance analysis. Obes Rev 2012;13:835-847.

-35 Blair SN, Cheng Y, Holder JS: Is physical activity or physical fitness more important in defining health benefits? Med Sci Sports Exerc 2001;33:S379-S399.

36 Sawada SS, Lee I, Naito H, Noguchi J, Tsukamoto K, Muto T, Higaki Y, Tanaka H, Blair S: Long-term trends in cardiorespiratory fitness and the incidence of type 2 diabetes. Diabetes Care 2010;33:1353-1357.

37 Riedl I, Yoshioka M, Nishida Y, Tobina T, Paradis R, Shono N, Tanaka H, St-Amand J: Regulation of skeletal muscle transcriptome in elderly men after 6 weeks of endurance training at lactate threshold intensity. Exp Gerontol 2010;45:896-903. 